\title{
Determination of atrazine, desethyl atrazine and desisopropyl atrazine in environmental water samples using hollow fiber-protected liquid-phase microextraction and high performance liquid chromatography
}

\author{
Jinfeng Peng, Jianxia Lü, Xialin Hu, Jingfu Liu*, and Guibin Jiang \\ State Key Laboratory of Environmental Chemistry and Ecotoxicology, Research Center for Eco-Environmental Sciences, \\ Chinese Academy of Sciences, P.O. Box 2871, Beijing 100085, China
}

Received May 22, 2006; accepted September 14, 2006; published online January 9, 2007

(C) Springer-Verlag 2007

\begin{abstract}
A new method based on hollow fiberprotected liquid-phase microextraction (LPME) was developed for the simultaneous determination of atrazine, desethyl atrazine and desisopropyl atrazine in environmental water samples. In LPME, analytes were extracted into 1-octanol immobilized in the micropores of a poly(vinylidene fluoride) porous hollow fiber membrane, and back extracted into the acceptor $(4 \mathrm{M} \mathrm{HCl})$ filled in the lumen of the hollow fiber. After LPME, the analytes trapped in the acceptor were analyzed with high-performance liquid chromatography after neutralization. The effect of extraction factors such as sample $\mathrm{pH}$, acceptor $\mathrm{pH}$, salinity, extraction time, stirring rate, and humic acid were studied. Under the optimized conditions, the limits of detection and relative standard deviations were respectively in the range of $0.5-1.0 \mu \mathrm{g} \mathrm{L}^{-1}$ and $3.9-4.7 \%(n=5)$. The proposed method was applied to determine atrazine, desethyl atrazine and desisopropyl atrazine in wastewater and groundwater samples. The three analytes were below the limits of detection, but good relative spiked recoveries over $90.1 \pm 5.9 \%$ at $5 \mu \mathrm{g} \mathrm{L}^{-1}$ spiked level were obtained.
\end{abstract}

\footnotetext{
* Author for correspondence. E-mail: jfliu@ rcees.ac.cn
}

Key words: Hollow fiber-protected liquid-phase microextraction; atrazine; desethyl atrazine; desisopropyl atrazine; high-performance liquid chromatography.

Atrazine, as a chloro-N-dialkyl-substituted triazine herbicide, was one of the most extensively used compounds for pre- and post-emergence weed control in agriculture during the past few decades [1-4]. Because of its possible human carcinogenicity and persistent toxicity, it has been considered to be a Priorty A chemical for potential groundwater contamination by the U.S. Environmental Protection Agency (EPA) [5] and been ranked highest 83 pesticides in the Agriculture Canada priority scheme for potential groundwater contaminants [6]. Moreover, its metabolites, desethyl atrazine (DEA) and desisopropyl atrazine (DIA) have similar toxicity as the parent atrazine (ATR) [7]. Therefore, a great attention was paid to determine these compounds in water, soil and organisms by some environmental analysis researchers recently. As most environmental samples are very complex and the concentrations of the analytes are usually quite low, an extraction and preconcentration step is necessary prior to determination.

Various methods including the classical liquidliquid extraction (LLE) [8], solid-phase extraction (SPE) [9-11], supercritical fluid extraction (SFE) $[12,13]$, liquid-phase microextraction (LPME) [14, 
15], solid-phase microextraction (SPME) [16-18], and coupled extraction techniques $[19,20]$ were applied for extraction and preconcentration of atrazines from various samples. However, most of these methods were not applicable for simultaneous extracting triazines and their metabolites as the metabolites are usually much more polar than the parent compounds. Megersa et al. [4] reported an automated supported liquid membrane (SLM) extraction procedure for trace enrichment of triazines and their metabolites in environmental and biological samples. This method exhibited excellent clean-up and low detection limits for both of triazines and their metabolites, but it required a special SLM set-up with three pumps and 4 valves. Hollow fiber membrane protected LPME, which includes the two phases and three phases extraction mode, was demonstrated to be a very efficient technique for extraction and preconcentration various analytes in complex matrixes $[21,22]$. Whereas the two phases mode of hollow fiber protected LPME was used to extract triazines [14], there is no report on simultaneous extracting triazines and their metabolites by hollow fiber protected LPME.

In this study, by immobilizing 1-octanol in the micropores of the polyvinylidene fluoride (PVDF) porous hollow fiber and filling the lumen of the fiber with $4 \mathrm{M} \mathrm{HCl}$ as the acceptor phase, a very simple and stable LPME device was developed for the extraction of ATR, DEA and DIA.

\section{Experimental}

\section{Materials and chemicals}

The hydrophobic polyvinylidene fluoride (PVDF) hollow fiber membrane (inner diameter $450 \mu \mathrm{m}$, wall thickness $125 \mu \mathrm{m}$, pore size $2.5 \mu \mathrm{m}$ ) was obtained from Motianmo company (www.tj-motian. com). The SEM photograph of the inner surface of the hollow fiber is shown in Fig. 1a. A $25-\mu \mathrm{L}$ microsyringe purchased from Shanghai Anpel Instrumental Co., LTD (www.anpel.com.cn) with a needle of $0.5 \mathrm{~mm}$-outer diameter was used to fill the acceptor into the lumen of the hollow fiber for extraction and flushing out the acceptor into a small glass vial $(200 \mu \mathrm{L})$ after extraction. HPLC-grade acetonitrile was purchased from J. T. Baker (www.jtbaker.nl).

Standard stock solutions $\left(100 \mathrm{mg} \mathrm{L}^{-1}\right)$ of atrazine (ATR) from Crescent Chemical Co., Inc. (www.crescentchemical.com), desethyl atrazine (DEA), and desisopropyl atrazine (DIA) obtained from Riedel-de Haen (www.riedeldehaen.de) were prepared by dissolving $0.25 \mathrm{mg}$ of the compounds in $2.5 \mathrm{~mL}$ acetonitrile. The solutions were stored in brown glass bottles and kept at $4{ }^{\circ} \mathrm{C}$. Fresh working solutions were prepared daily by appropriate dilution of the stock solutions. 1-Octanol (HPLC grade) was purchased from SigmaAldrich (www.sigmaaldrich.com). Humic acid was purchased from Acros Organics (www.acros.com). All the other chemicals were analytical grade reagents and purchased from Beijing Chemicals
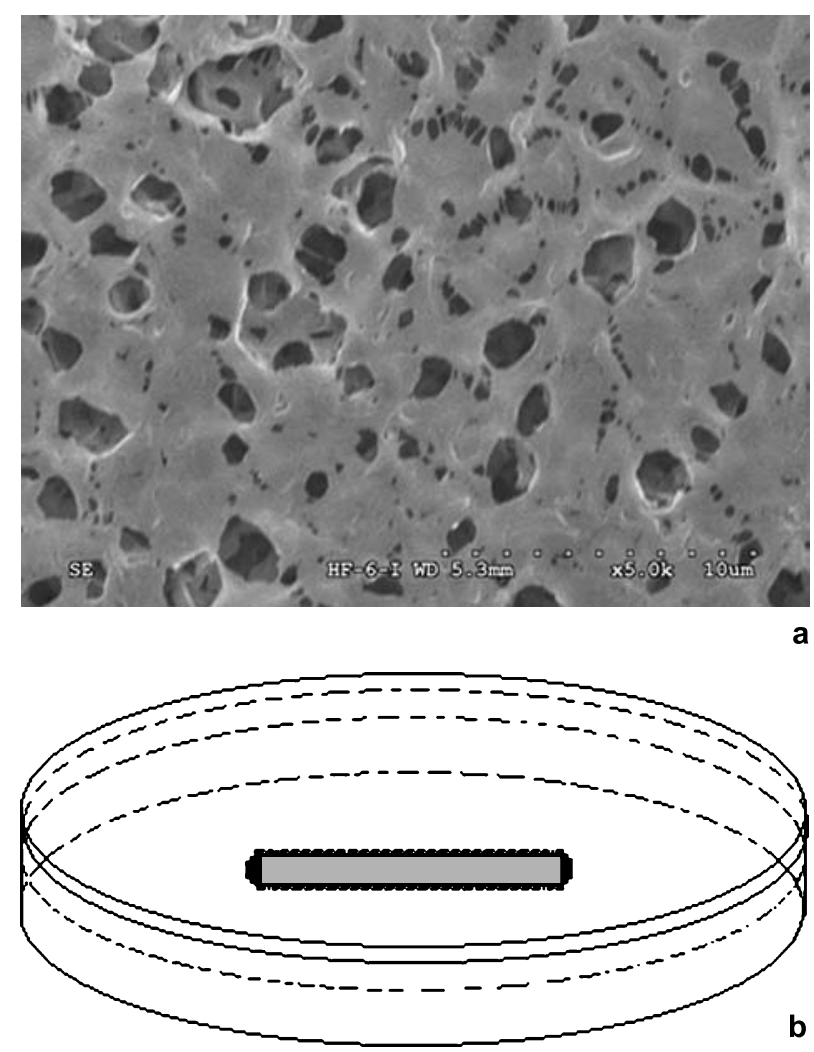

Fig. 1. (a) Scanning electron microscopic image of inner surface of the hollow fiber magnified by 5000 times. (b) Schematic diagram for hollow fiber-protected liquid-phase microextraction

Corporation (www.bj-chemical.com) and ultrapure water (EASYpure LF) was used throughout.

\section{Hollow fiber-protected liquid-phase microextraction}

The experimental setup of hollow fiber-protected LPME was shown in Fig. 1b. Extraction was conducted as follows: the PVDF porous hollow fiber cut manually and carefully into $5.1 \mathrm{~cm}$-length was immersed in 1-octanol for $10 \mathrm{~min}$. The hollow fiber was taken out and its outside and inside was flushed five times with water in a washing bottle and water in a $0.5 \mathrm{~mL}$ microsyringe, respectively. Then the hollow fiber was connected with the needle of the microsyringe holding $\sim 20 \mu \mathrm{L}$ acceptor solution. Thereafter, the plunger of the microsyringe was depressed to flush out $\sim 20 \mu \mathrm{L}$ acceptor solution to wash and fill the lumen of the hollow fiber without any air bubbles. After that, the two ends were sealed with heated tweezers. By this preparation, the obtained hollow fiber-protected liquid-phase microextraction device had an effective fiber length of $\sim 5.0 \mathrm{~cm}$ with acceptor phase volume of $\sim 8 \mu \mathrm{L}$. After this, the hollow fiber was ready for extraction. During extraction, the solution can be stirred at a very high speed. The volume of extracted aqueous solution was $50 \mathrm{~mL}$ in a $100-\mathrm{mL}$ petri dish with addition of sodium chloride at certain concentration. Then the petri dish was covered with its glass cap. After extracting for the prescribed time, the hollow fiber was taken out from the aqueous solution and one sealed end was cut open for connecting with the microsyringe, then the other sealed end was cut open to facilitate flushing out the acceptor solution into the $200-\mu \mathrm{L}$ glass vial with the microsyringe. After that, $8 \mu \mathrm{L}$ of sodium 
hydroxide at certain concentration was added into the glass vial to neutralize the acid acceptor solution. Finally, the total solution of $\sim 16 \mu \mathrm{L}$ was retracted into an $25-\mu \mathrm{L}$ HPLC microsyringe (Agilent, USA) for injection. The used fiber was discarded and a fresh one was used for the next experiment.

\section{HPLC determination}

The LC-VP liquid chromatographic instrument (Shimadzu, Japan) consists of a SCL-10Avp system controller, two LC-10ATvp pumps, and a SPD-M10Avp diode array detector (DAD) set at $220 \mathrm{~nm}$. Data acquisition and process were accomplished with a Class-VP Workstation (Shimadzu, Japan). The analytical column was a $150 \times 4.6 \mathrm{~mm}$ I.D. $\mathrm{C}_{18}$ column (Zorbax RX-C18, Agilent, USA, $5 \mu \mathrm{m}$ particles). LC separation of ATR, DEA and DIA was conducted by using a mixture of acetonitrile and water (adjust to $\mathrm{pH} 7.0$ with $5 \mathrm{nM}$ phosphate buffer) as mobile phase at a flow rate of $0.8 \mathrm{~mL} \mathrm{~min}^{-1}$. The gradient profile was: kept $20 \%$ acetonitrile in $0-5 \mathrm{~min}$, then increased from 20 to $70 \%$ in $5-8 \mathrm{~min}$ and kept $70 \%$ for $7 \mathrm{~min}$.

\section{Sample collection}

Wastewater was collected at a sewage outfall of a wastewater treatment factory in Beijing. Groundwater was collected from a deep well in west suburb of Beijing. These samples were all stored at the temperature of $4{ }^{\circ} \mathrm{C}$ after collection.

\section{Results and discussion}

\section{Effect of sample solution $\mathrm{pH}$ and acceptor solution $\mathrm{pH}$}

In the three phases LPME, the $\mathrm{pH}$ of the sample solution phase (donor phase) and the acceptor phase play very important roles. Experiments were conducted to

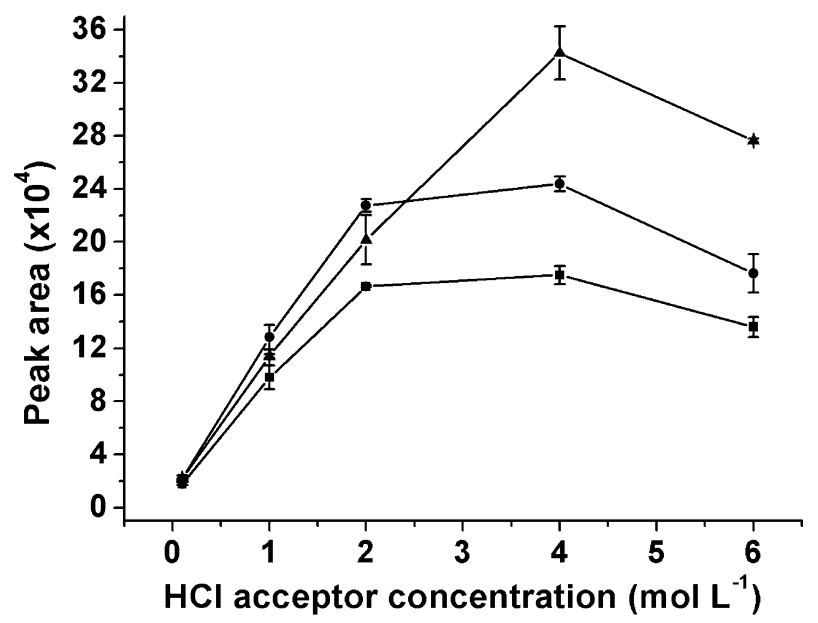

Fig. 2. Effect of acceptor $\mathrm{pH}$ on the extraction efficiency. Buffer solutions ( $\mathrm{pH} 7.0$ adjusted by $5 \mathrm{mM}$ phosphate buffer, $50-\mathrm{mL}$ ) spiked with $50 \mu \mathrm{g} \mathrm{L}^{-1}$ of ATRs were added $5.0 \mathrm{~g} \mathrm{NaCl}$ and extracted with various concentration $\mathrm{HCl}$ acceptor solutions for $30 \mathrm{~min}$ at the normal stirring rate. $\mathbf{\Delta}$, ATR; $\bullet$ DEA; $\mathbf{}$, DIA optimize the $\mathrm{pH}$ of both the donor phase and the acceptor phase. According to the basic principle of extraction/back extraction, adjusting the acceptor phase $\mathrm{pH}$ to a suitable value can keep the analytes ionized, which ensures that the ionized analyte molecules are irreversibly trapped and thereby concentrated. In this present study, up to $6 \mathrm{M} \mathrm{HCl}$ were used as the acceptor for trapping these analytes and the results are shown in Fig. 2. As can be seen, the extraction efficiency increased quickly when the $\mathrm{HCl}$ concentration varied from 0 to $2 \mathrm{M}$, and followed a slow increase from 2 to $4 \mathrm{M}$, then began to decrease at $4 \mathrm{M}$ for DEA and DIA. But for ATR, the extraction efficiency reached the highest at $4 \mathrm{M} \mathrm{HCl}$ followed by descent. Therefore, $4 \mathrm{M} \mathrm{HCl}$ which is the most suitable acid concentration for the ionization of the three analytes was chosen as the final acceptor in the following studies.

For LPME of a weak organic base and acid, the extraction efficiency depends on the $\mathrm{pH}$ of sample solution as well. The sample solutions were often adjusted to appropriate alkalinity to de-ionize atrazines and their metabolites for obtaining higher extraction efficiency. Figure 3 showed the profiles of the extraction efficiency with varied $\mathrm{pH}$, which indicates that the extraction efficiencies improved significantly with the increasing of $\mathrm{pH}$ and then increased very slowly over $\mathrm{pH} 3.0$. Based on this investigation, a $\mathrm{pH}>3.0$ is thus recommended, and we chose $\mathrm{pH}$ 7.0 as the final sample solution $\mathrm{pH}$ value for the following studies.

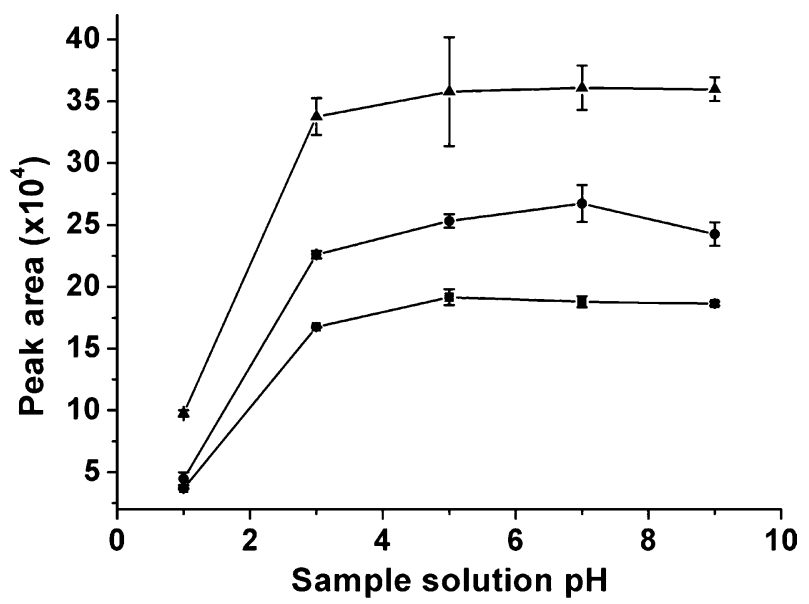

Fig. 3. Effect of sample solution $\mathrm{pH}$ on the extraction efficiency. various $\mathrm{pH}$ buffer solutions ( $\mathrm{pH}$ adjusted by $5 \mathrm{mM}$ phosphate buffer, $50-\mathrm{mL}$ ) spiked with $50 \mu \mathrm{g} \mathrm{L}^{-1}$ of ATRs were added $5.0 \mathrm{~g} \mathrm{NaCl}$ and extracted with $4.0 \mathrm{M} \mathrm{HCl}$ for $30 \mathrm{~min}$ at the normal stirring rate. $\mathbf{\Delta}$, ATR; •, DEA; $\mathbf{}$, DIA 


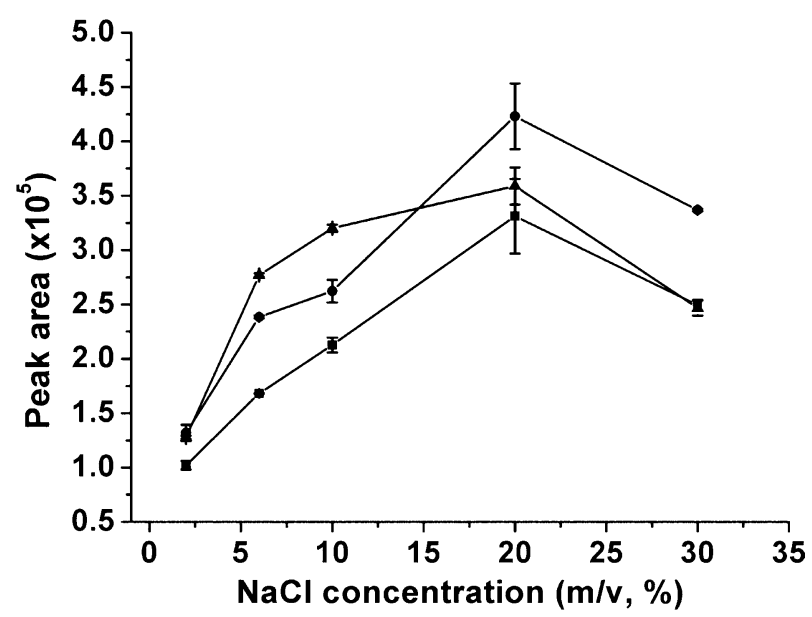

Fig. 4. Effect of salt addition in sample matrix on the peak area of ATRs. Buffer solutions ( $\mathrm{pH} 7.0$ adjusted by $5 \mathrm{mM}$ phosphate buffer, $50-\mathrm{mL}$ ) spiked with $50 \mu \mathrm{g} \mathrm{L}^{-1}$ of ATRs were added various amount of $\mathrm{NaCl}$ and extracted with $4.0 \mathrm{M} \mathrm{HCl}$ for $30 \mathrm{~min}$ at the normal stirring rate. $\mathbf{\Delta}$, ATR; $\bullet$, DEA; $\mathbf{\square}$, DIA

\section{Effect of salinity}

In most traditional extraction processes, salt was often added into the sample solution for improving the extraction efficiency. In this study, varied amounts of sodium chloride $(\mathrm{NaCl})$ were added into the sample solution to investigate the effect of salinity on the extraction. Figure 4 shows that for the three analytes, the extraction efficiency increased with the $\mathrm{NaCl}$ concentration up to $20 \%$ and followed by decreasing with further increasing of $\mathrm{NaCl}$ concentration. This phenomenon can be explained by the two simultaneously occurring processes: the salting out effect, and the electrostatic interactions between polar molecules and salt ions in sample solution. At the beginning, the former process played the predominant role. But the salt molecules began to interact with analyte molecules when salt concentration increased further, which directly leaded to the decrease of the respond. Therefore, $20 \% \mathrm{NaCl}$ was adopted as the final addition in the following studies.

\section{Effect of stirring rate and extraction time}

For hollow fiber-protected LPME, very high stirring rate could be used to speed the extraction dynamic equilibrium since the hollow fiber can protect the organic solvent and the acceptor solution. In the experiments, keeping the sample solution not to spill from the petri dish, the stirring rate was divided into three different classes, low, middle (normal) and high. The

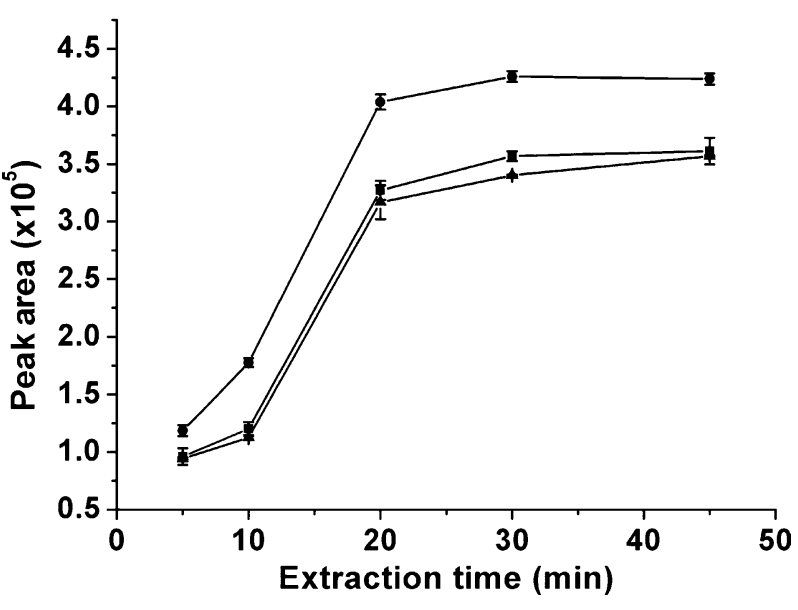

Fig. 5. Effect of extraction time on the peak area of ATRs. Buffer solutions ( $\mathrm{pH} 7.0$ adjusted by $5 \mathrm{mM}$ phosphate buffer, $50-\mathrm{mL}$ ) spiked with $50 \mu \mathrm{g} \mathrm{L}^{-1}$ of ATRs were added $10.0 \mathrm{~g} \mathrm{NaCl}$ and extracted with $4.0 \mathrm{M} \mathrm{HCl}$ for different time at the normal stirring

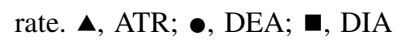

results showed that for the extraction time of $30 \mathrm{~min}$, the middle-stirring rate was enough to let the extraction reach equilibrium. Thereafter, the middle-stirring rate was chosen for the following investigation.

By a common rule, the amount of target compounds extracted increases with prolong of extraction time until extraction reaches equilibrium. Experiment results shown in Fig. 5 indicate that, for all these three analytes, the peak areas reached the highest at the extraction time of $30 \mathrm{~min}$ and then kept constant with further increasing of extraction time. Consequently, 30 min was chosen in the following studies.

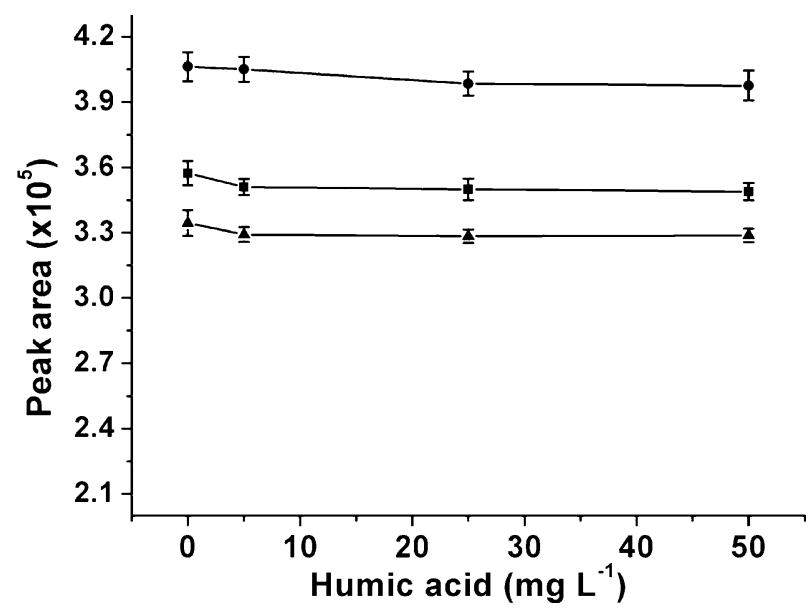

Fig. 6. Effect of humic acid on the peak area of ATRs. Buffer solutions ( $\mathrm{pH} 7.0$ adjusted by $5 \mathrm{mM}$ phosphate buffer, $50-\mathrm{mL}$ ) spiked with $50 \mu \mathrm{g} \mathrm{L}^{-1}$ of ATRs were added $10.0 \mathrm{~g} \mathrm{NaCl}$ and varied amount of humic acid, extracted with $4.0 \mathrm{M} \mathrm{HCl}$ for $30 \mathrm{~min}$ at the normal stirring rate. $\mathbf{\Lambda}$, ATR; $\bullet$ DEA; $\mathbf{\square}$, DIA 
Table 1. Some analytical performance date of the proposed method

\begin{tabular}{llllll}
\hline Analytes & $\begin{array}{l}\text { Linearity range } \\
\left(\mu \mathrm{g} \mathrm{L}^{-1}\right)\end{array}$ & $\begin{array}{l}\text { Correlation } \\
\text { coefficient }\left(r^{2}\right)\end{array}$ & $\begin{array}{l}\text { Limit of detection } \\
\left(\text { LODs, } \mu \mathrm{g} \mathrm{L}^{-1}\right)\end{array}$ & $\begin{array}{l}\text { Enrichment } \\
\text { factor }\left(E_{e}\right)\end{array}$ & $\begin{array}{l}\text { RSD }(\%)^{\mathrm{a}} \\
(n=5)\end{array}$ \\
\hline DIA & $2.5-100$ & 0.9987 & 1.0 & 46 & 4.7 \\
DEA & $2.5-150$ & 0.9997 & 0.8 & 51 & 3.9 \\
ATR & $2.5-100$ & 0.9986 & 0.5 & 44 & 3.5 \\
\hline
\end{tabular}

${ }^{\mathrm{a}}$ Determined at a concentration of $10 \mu \mathrm{g} \mathrm{L}^{-1}$ for each analyte.

\section{Effect of humic acid}

The effect of humic acid on the extraction was studied with varied concentration of $0-50 \mathrm{mg} \mathrm{L}^{-1}$, covering the range in most environment surface water [23]. The experimental results shown in Fig. 6 indicate that the addition of humic acid did not significantly affect the extraction efficiency. This is because humic acid $\left(\mathrm{pK}_{\mathrm{a}}=5.5\right)$ [19] presented mainly in ionized form at sample $\mathrm{pH} 7.0$ and thus prohibited its transfer through the hollow fiber protected liquid membrane of the LPME device. The ionization of humic acid also decreased its binding to analytes that is helpful for extraction of analytes. On the other hand, the porous hollow fiber wall can also exclude the high molecular weight humic acid.

\section{Analytical performance and application}

In order to validate the method, linearity, limits of detection, enrichment factors and repeatability were investigated. Peak areas were used for calibration and quantification. Dynamic linearity range was evaluated by the calibration curve of peak areas versus concentrations. The limits of detection (LODs) were estimated based on signal-to-noise ratio of $3(S / N=3)$. Enrichment factor $\left(E_{e}\right)$ was defined as:

$$
E_{e}=\frac{C_{A}}{C_{S}}
$$

where $C_{A}$ and $C_{S}$ are the concentrations of analytes in the acceptor solution and extracted sample solution, respectively. The precisions were calculated by five replicate experiments. As shown in Table 1, each analyte exhibited good linearity with correlation coefficient $r^{2}>0.998$ in the studied range. The limits of detections were in the range of $0.5-1.0 \mu \mathrm{g} \mathrm{L}^{-1}$. The enrichment factors for DIA, DEA and ATR were 46, 51 and 44. And the relative standard deviations (RSDs) were less than $5 \%$, respectively.

\section{Real sample analysis}

The applicability of the proposed method was evaluated by analysis of two real environmental water sam-
Table 2. Some characteristics of the water samples and the relative recoveries of DIA. DEA and ATR at $5 \mu \mathrm{g} \mathrm{L}^{-1}$ spiking level (mean $\pm \mathrm{s}, n=3$ )

\begin{tabular}{lrcrrr}
\hline Samples & pH & \multicolumn{1}{l}{$\begin{array}{l}\text { DOC } \\
\left(\mathrm{mg} \mathrm{L}^{-1}\right)\end{array}$} & DIA (\%) & DEA (\%) & ATR (\%) \\
\hline Wastewater & 7.22 & 6.78 & $98.8 \pm 5.6$ & $97.6 \pm 4.9$ & $101.4 \pm 6.5$ \\
Groundwater & 7.52 & 15.97 & $92.3 \pm 5.2$ & $93.7 \pm 6.8$ & $90.1 \pm 5.9$ \\
\hline
\end{tabular}

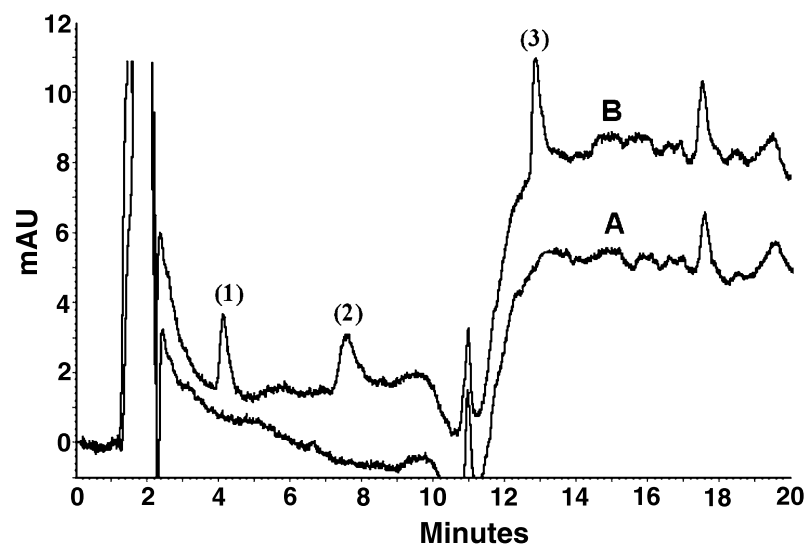

Fig. 7. Typical chromatograms of wastewater. (A) wastewater; (B) wastewater spiked with $2 \mu \mathrm{g} \mathrm{L}{ }^{-1}$ DIA. DEA and ATR standard. (1) DIA; (2) DEA; (3) ATR

ples, wastewater and groundwater. The characteristics of the samples and the analytical results were shown in Table 2. In both of the two samples, ATR, DEA and DIA were all below their detection limits, so $5 \mu \mathrm{g} \mathrm{L}^{-1}$ ATR, DEA and DIA standards were spiked in the $50 \mathrm{~mL}$ water samples. The relative spiked recoveries were calculated by the concentration found to that spiked. Table 2 showed that the relative spiked recoveries were in the range of $90.1-101.4 \%$. The typical chromatograms were shown in Fig. 7.

\section{Conclusions}

A hollow fiber-protected liquid-phase microextraction method was proposed for simultaneous extraction and enrichment of ATR, DEA and DIA in environmental water samples. This extraction procedure was 
coupled with HPLC for the analysis of these analytes with low limits of detection and good repeatability. The proposed procedure was applied to determine ATR, DEA and DIA in wastewater and groundwater with good relative spiked recoveries, which indicates that the matrix interferences could be eliminated effectively.

Acknowledgements. This work was jointly supported by the National Natural Science Foundation of China (20477052) and the National Key Project for Basic Research (2002CB412308).

The authors are very grateful to Professor Z. W. Cai from Hongkong Baptist University for providing atrazines standards and to Professor Y. B. Fan and Dr. H. Zhong from membrane research group of Research Center for Eco-Environmental Sciences, Chinese Academy of Sciences for providing different hollow fiber membranes for this study.

\section{References}

[1] Mills M S, Thurman E M (1994) Preferential dealkylation reactions of s-triazine herbicides in the unsaturated zone. Environ Sci Technol 28: 600

[2] Hernandez F, Hidalgo C, Sancho J V, Lopez F J (1998) Coupled-column liquid chromatography applied to the tracelevel determination of triazine herbicides and some of their metabolites in water samples. Anal Chem 70: 3322

[3] Megersa N, Jonsson J A (1998) Trace enrichment and sample preparation of alkylthio-s-triazine herbicides in environmental waters using a supported liquid membrane technique in combination with high-performance liquid chromatography. Analyst 123: 225

[4] Megersa N, Chimuka L, Solomon T, Jonsson J A (2001) Automated liquid membrane extraction and trace enrichment of triazine herbicides and their metabolites in environmental and biological samples. J Sep Sci 24: 567

[5] U.S. Environmental Protection Agency (1985) EPA draft final list of recommendations for chemicals in the National Survey for Pesticides in Groundwater. Chemical Regulations Reporter, p 1033

[6] McRae B, Planning and Priorities Division, Pesticides Directorate, Agriculture Canada (1991) The characterization and identification of potentially leachable pesticides and areas vulnerable to groundwater contamination by pesticides in Canada. Backgrounder, Ottawa, p 1

[7] Shipitalo M J, Owens L B (2003) Atrazine, deethylatrazine, and deisopropylatrazine in surface runoff from conservation tilled watersheds. Environ Sci Technol 37: 944

[8] Jeannot R, Sabik H, Sauvard E, Genin E (2000) Application of liquid chromatography with mass spectrometry combined with photodiode array detection and tandem mass spectrometry for monitoring pesticides in surface waters. J Chromatogr A 879: 51

[9] Huang S B, Stanton J S, Lin Y, Yokley R A (2003) Analytical method for the determination of atrazine and its dealkylated chlorotriazine metabolites in water using SPE sample preparation and GC-MSD analysis. J Agric Food Chem 51: 7252

[10] Corcia A D, Crescenzi C, Guerriero E, Samperi R (1997) Ultratrace determination of atrazine and its six major degradation products in water by solid-phase extraction and liquid chromatography-electrospray/mass spectrometry. Environ Sci Technol 31: 1658

[11] Melo L F C, Collins C H, Jardim I C S F (2005) Highperformance liquid chromatographic determination of pesticides in tomatoes using laboratory-made $\mathrm{NH} 2$ and $\mathrm{C}-18$ solid-phase extraction materials. J Chromatogr A 1073: 75

[12] Papilloud S, Haerdi W, Chiron S, Barceló D (1996) Supercritical fluid extraction of atrazine and polar metabolites from sediments followed by confirmation with LC-MS. Environ Sci Technol 30: 1822

[13] Pensabene J W, Fiddler W, Donoghue D J (2000) Supercritical fluid extraction of atrazine and other triazine herbicides from fortified and incurred eggs. J Agric Food Chem 48: 1668

[14] Shen G, Lee H K (2002) Hollow fiber-protected liquid-phase microextraction of triazine herbicides. Anal Chem 74: 648

[15] Bagheri H, Khalilian F (2005) Immersed solvent microextraction and gas chromatography-mass spectrometric detection of s-triazine herbicides in aquatic media. Anal Chim Acta 537: 81

[16] Moder A, Popp P, Eisert R, Pawliszyn J (1999) Determination of polar pesticides in soil by solid phase microextraction coupled to high-performance liquid chromatography-electrospray mass spectrometry. Fresen J Anal Chem 363: 680

[17] Basheer C, Lee H K (2004) Hollow fiber membrane-protected solid-phase microextraction of triazine herbicides in bovine milk and sewage sludge samples. J Chromatogr A 1047: 189

[18] Ferrari R, Nilsson T, Arena R, Arlati P, Bartolucci G, Basla R, Cioni F, Carlo G D, Dellavedova P, Fattore E, Fungi M, Grote C, Guidotti M, Morgillo S, Muller L, Volante M (1998) Inter-laboratory validation of solid-phase microextraction for the determination of triazine herbicides and their degradation products at $\mathrm{ng} / 1$ level in water samples. J Chromatogr A 795: 371

[19] Vandecasteele K, Gaus I, Debreuck W, Walraevens K (2000) Identification and quantification of 77 pesticides in groundwater using solid phase coupled to liquid-liquid microextraction and reversed phase liquid chromatography. Anal Chem 72: 3093

[20] Khrolenko M, Dzygiel P, Wieczorek P (2002) Combination of supported liquid membrane and solid-phase extraction for sample pretreatment of triazine herbicides in juice prior to capillary electrophoresis determination. J Chromatogr A 975: 219

[21] Psillakis E, Kalogerakis N (2003) Developments in liquidphase microextraction. Trac-Trends Anal Chem 22: 565

[22] Rasmussen K E, Pedersen-Biergaard S (2004) Developments in hollow fibre-based, liquid-phase microextraction. TracTrends Anal Chem 23: 1

[23] Lutzhoft H C H, Vaes W H J, Freidig A P, Halling-Sorensen B, Hermens J L M (2000) Influence of pH and other modifying factors on the distribution behavior of 4-quinolones to solid phases and humic acids studied by "negligible-depletion" SPME-HPLC. Environ Sci Technol 34: 4989 